\title{
Linking Education and Research: A Roadmap for Higher Education Institutions at the Dawn of the Knowledge Society
}

Per Berglund, ${ }^{\mathrm{a}}$ Per Dannetun, ${ }^{\mathrm{b}}$ Wai Lee Chan, ${ }^{\mathrm{c}} \mathrm{Julie}$ Gold, ${ }^{\mathrm{d}}$ Sam Han, ${ }^{\mathrm{c}}$ Heidi Hansson, ${ }^{\mathrm{e}}$ Simon Harvey, ${ }^{\mathrm{d}}$ Jun Song Huang, ${ }^{\mathrm{f}}$ Ann-Charlotte Larsson, ${ }^{\mathrm{g}}$ Steven Linton, ${ }^{\mathrm{h}}$ Gerald McInerney, ${ }^{\mathrm{i}}$ Marie Magnell, ${ }^{\mathrm{a}}$ Oleg Popov, ${ }^{\mathrm{e}}$ Nils-Hassan Quttineh, ${ }^{\mathrm{b}}$ Tobias Richards, ${ }^{\mathrm{j}}$ Juha Song, ${ }^{\mathrm{c}}$ Adam D. Switzer, ${ }^{\mathrm{c}}$ Kristina Tegler Jerselius, ${ }^{\mathrm{k}}$ Susanne Vikström, ${ }^{\mathrm{e}}$ Martin Wikström, ${ }^{1}$ Kang Yang Trevor Yu, ${ }^{\mathrm{c}}$ Jesvin Puay-Hwa Yeo, ${ }^{\mathrm{c}}$ Nabil Zary, ${ }^{\mathrm{c}}$ Hans Pohl, ${ }^{\mathrm{m}}$ Ulf Ellervik*,

${ }^{a}$ KTH Royal Institute of Technology, Sweden ${ }^{\mathrm{b}}$ Linköping University, Sweden

'Nanyang Technological University, Singapore ${ }^{\mathrm{d} C h a l m e r s ~ U n i v e r s i t y ~ o f ~ T e c h n o l o g y, ~ S w e d e n ~}$ eUmeå University, Sweden ${ }^{\mathrm{f}}$ National Institute of Education, Singapore 'Linnaeus University, Sweden hÖrebro University, Sweden iKarolinska Institutet, Sweden jUniversity of Borås, Sweden

${ }^{\mathrm{k}}$ Swedish Higher Education Authority, Sweden ${ }^{1}$ Royal Swedish Academy of Engineering Sciences, Sweden ${ }^{\mathrm{m}}$ The Swedish Foundation for International Cooperation in Research and Higher Education (STINT), Sweden

${ }^{\mathrm{n}}$ Lund University, Sweden

* Corresponding author. 


\section{Abstract}

In an era characterized by a move towards a "knowledge society", universities are central in fostering "knowledgeability", that is the reflexive understanding of knowledge in knowledge societies. The objective of "knowledgeability" can be met through creating a stronger link between education and research. Furthermore, overall student performance, for example in critical thinking and problem solving, can be improved if research-related activities are incorporated into the curriculum.

The aim of this paper is to use international examples to discuss the researcheducation nexus from four different perspectives, namely context, policy, implementation and quality, with case studies from higher education institutions in Singapore and Sweden.

We suggest that different integrative technologies can be used to enhance the links, but it will be essential to consider the inputs of training, service and support in using new technology. Interestingly, the act of evaluating the link between education and research will increase awareness of this linkage by stakeholders involved in both education and research. In turn the link can be strengthened, contributing to increased quality in both education and research.

\section{Introduction}

In an age of increased economic growth and societal transformation that is moving towards what social scientists have dubbed a "knowledge society", universities are central in keeping small nations apace with other larger nations (Stehr, 1994,
The term "knowledge society", which originated in sociology and social theory in the 1990s, was first used in the work of German sociologist Nico Stehr. It refers to the increased importance of knowledge in a range of spheres, including politics, economics, and culture, and refers back to earlier concepts such as "post-industrial society" (Böhme \& Stehr, 1986). The "post-industrial society" was supposed to be driven by the rise of information and service as two of the major sectors for economic growth of the future and subsequently constitutes a major shift away from a manufacturingoriented mode of production to a knowledge-based one (Bell, 1973).

In higher education, the realities of knowledge societies have spawned certain ideas about the role of universities. In particular, the widely influential concept of the "Triple Helix" suggests that the function of universities is understood as supporting growth in industrial production and business (Etzkowitz \& Leydesdorff, 1995; Välimaa \& Hoffman, 2008). Furthermore, universities play a vital role in knowledge societies through knowledge expansion in the form of research and, more importantly, relaying knowledge through education (Ranga \& Etzkowitz, 2013).

Thus, fostering knowledge about knowledge, which Stehr calls "knowledgeability", is of utmost importance. The objective of "knowledgeability" can be met through a greater connection between education and research. More specifically, when "knowledge" is fluid and society is changing rapidly, adopting an ethos of research becomes necessary to 
generate graduates equipped for the challenges underlying knowledge societies (Stehr, 2008).

The aim of this paper is to develop a roadmap for strengthening the links between education and research at higher education institutions, using an inductive approach based on international practices. In August 2017, The Swedish Foundation for International Cooperation in Research and Higher Education organized an intensive one-week summer school, addressing the links between education and research. Participants in the summer school were nominated from higher education institutions in Singapore and Sweden, with the goal of creating an assembly of participants representing different positions and scientific disciplines in the higher education system. The overarching idea of the summer school was to stimulate interaction between the participants, who, as a collective, contributed substantial knowledge on the topic. Data were collected through a combination of group work, short individual presentations, workshops, and visits to different teaching and learning environments in Singapore.

At all levels, mechanisms influence how education and research are connected. This can be discussed from different perspectives, such as context, policy, implementation, and quality assessment. Each teaching situation is set in a context with specific obstacles and opportunities, and the link between education and research is not always obvious. However, governments, universities, and institutions can set up policies to enhance this link, thus implementing research in the teaching setting, and vice versa. Finally, the quality of the enhanced link between education and research must be monitored and assessed.
In this paper, we outline a systematic procedure for linking education and research. Then, case studies from Singapore and Sweden serve as examples of how education and research can belinked and how the success of such implementations may be measured.

\section{The context: Higher education institutions in Singapore and Sweden}

The Singaporean funding system for higher education institutions is similar to that of many American universities and includes endowments as well as income from tuition fees and external research grants. This may mean that university leadership is in a relatively stronger position to focus on education, compared to that of some Swedish higher education institutions. Higher education institutions in Sweden are, in most cases, agencies in their own right that report directly to the government and the Ministry of Education and Research. They enjoy extensive freedom within the framework of the statutes, ordinances and regulations laid down by the government. Higher education institutions have to offer education based on an academic or artistic foundation and proven experience. In addition, there are other obligations such as research and artistic development.

However, while individual academics often are involved in both teaching and research, the former is not always their highest priority. Also, the incentives to teach and develop new teaching methods are not always clear. A central reason for thelack of incentives is the incomestructure ofSwedish highereducation institutions. In recent years, increases in research funding have not been accompanied by an ${ }_{3}$ 
equivalent increase in teaching funding, resulting in a reduction in the relative proportion of the directeducation funding allocated to Swedish higher education institutions. Furthermore, the size of different funding streams varies significantly between Swedish higher education institutions (see Figure 1). At major research universities, the amounts allocated to teaching are relatively smaller than the research funding streams, leading to a situation where teaching efforts have a lower priority at the individual level, and research is more valued for career development and tenure. In addition, external research grants are in some cases substantial and directed to individual researchers or research groups. While such focus on individual research groups is important for research quality, an excessive dominance of such funding over direct teaching funds may result in inertia when implementing overarching university strategies, including new teaching goals.

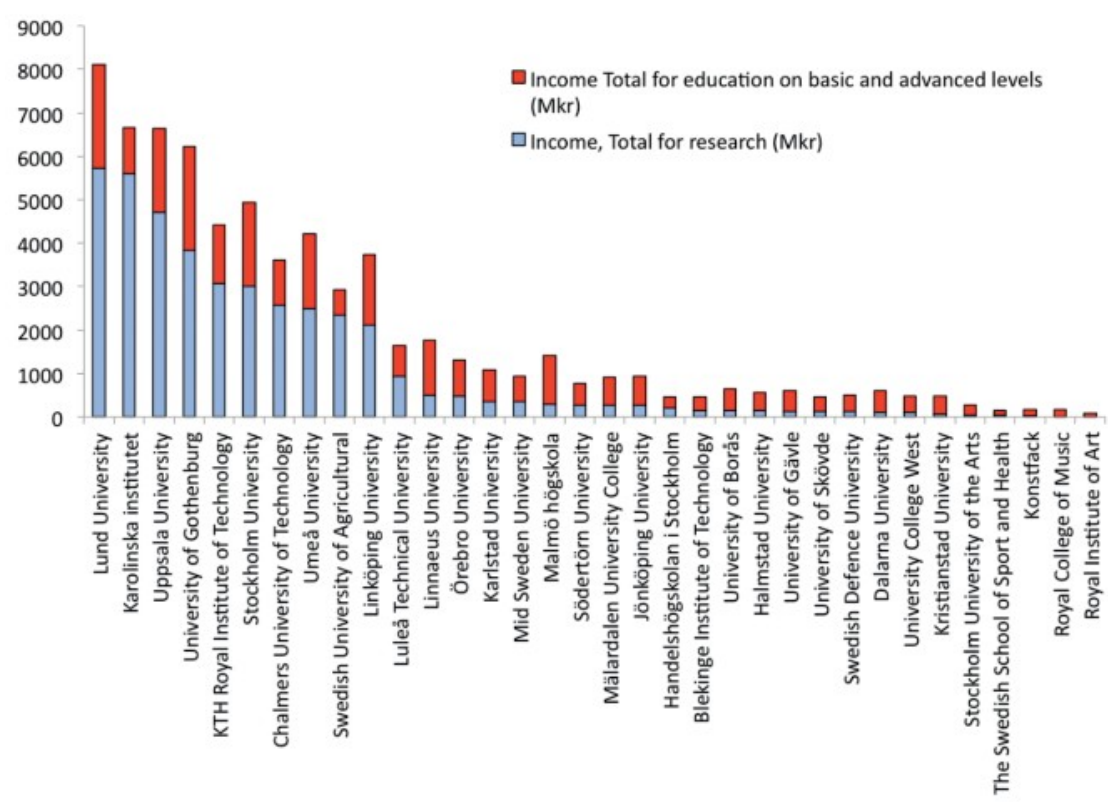

Figure 1: The distribution of funding streams to various Swedish higher education institutions. Source: the Knowledge Foundation (2016) 


\section{Policy}

The policy-related challenges at some Singaporean and Swedish universities include the need for greater emphasison education, development of innovative curricula that are connected to research, and a closer relationship between education and research.

Policy issues at the national level are characterized by the formulation of broad policy objectives related to societal education and research needs, specific assignments from government to higher education institutions, performance agreements between state and university, and decisions on funding allocated to theuniversities. Singapore and Sweden have a similar aim to become knowledge-based societies, which clearly requires the further development of research- and enquiry-based learning.

In Singapore this projection is driven primarily by the Ministry of Education and fuelled by reviews and recommendations including those of the Committee on University Education Pathways Beyond 2015. This report specifically proposed increasing the number of places at universities and developing new applied degree pathways that will provide more opportunities and choices in a diverse university landscape. The autonomous universities in Singapore then include such objectives into their three-year rolling plans with the aim of producing graduates that meet the needs of the country as a whole. The committee noted that In order to enhance the close nexus between education and research, students and staff at these institutions should have the opportunity to work with industries and local enterprises on research projects that are primarily applied in nature, and would involve solving realworld problems. These research/project work opportunities would be offered to undergraduates to enhance their learning experience and industry-relevance.

University study programmes in Singapore thus primarily aim for a mix between theory and practice, with associated work placements or industrial experience.
Despite the variations across programmes, students are generally given equal opportunities to take up internships and obtain work experience in companies, while research opportunities are commonly reserved for the top performers in a cohort.

In Sweden, the national qualitative targets for higher education are mandated bylaw. According to the Swedish Higher Education Ordinance, the national qualitative targets aim at developing for example the students' ability to make independent and critical assessments, their capability to identify, formulate and solve problems independ-ently, and their preparedness to deal with changes in working life.

Overall, despite the needs of knowledgebasedeconomies to build knowledgeability throughresearchanddespitenationalqualitative targets emphasising research-based education in both Singapore and Sweden, it seems that the disconnect between edu-cation and research persists. Universities in both countriesarefaced with issues related to governanceand policies thateitherencourage or hinder the incorporation of research into the educational experience. One example in the Swedish context, as mentioned above, is thehighlevel of externalresearch funding compared to directfunding forteaching, which may adversely affect the ability of the central administration to implement overall strategic plans and set priorities.

However, university level policies and individual schools and departments may also create a culture and provide incentives for researchers to connect education and research. The most common model today is to award titles of recognition, such as "Excellent Teaching Practitioner", after evaluation and fulfilled requirements set up at each local higher education institution (Winka, 2017). Further, open seminars encouraging interaction between students and faculty at all levels, as well as incentives for curriculum development could be explored.

Below, two case studies further exemplify how policies at different levels influence the link between education and research. 


\section{Case Study A}

KTH Royal Institute of Technology, Sweden

KTH Royal Institute of Technology is a research-intensive university with more than 14,000 students at various levels ranging from undergraduate to postgraduate or doctoral levels. At $\mathrm{KTH}$, education and research are well integrated at some schools and departments, but there are problems related to how education is prioritized and there is clearly a status difference between teaching and research (Geschwind, Magnell \& Söderlind, 2016). One reason for this is related to financing. At $\mathrm{KTH}$, the governmental funding (Figures 1 and 2) for education at bachelor and master levels comprises $24 \%$ of the total funding, while that for research(including $\mathrm{PhD}$ education) is $26 \%$, and the remaining $50 \%$ is external funding for research.
The situation differs between the various schools at KTH, but in general the salary of a faculty member is covered to only about $50 \%$ from governmental funding. This means that the remaining part of the salary must be obtained from external research funding sources. The incentive for a faculty member to engage in education is thus low and much effort is devoted to applying for external research funding. Another finance-related reason is that there is necessarily more administrative support required for education that for research, due to theneed for administrative services such as a central admissions office and student counselling services. Consequently, the financial incentive for a faculty member to engage in teaching is lowered even further.

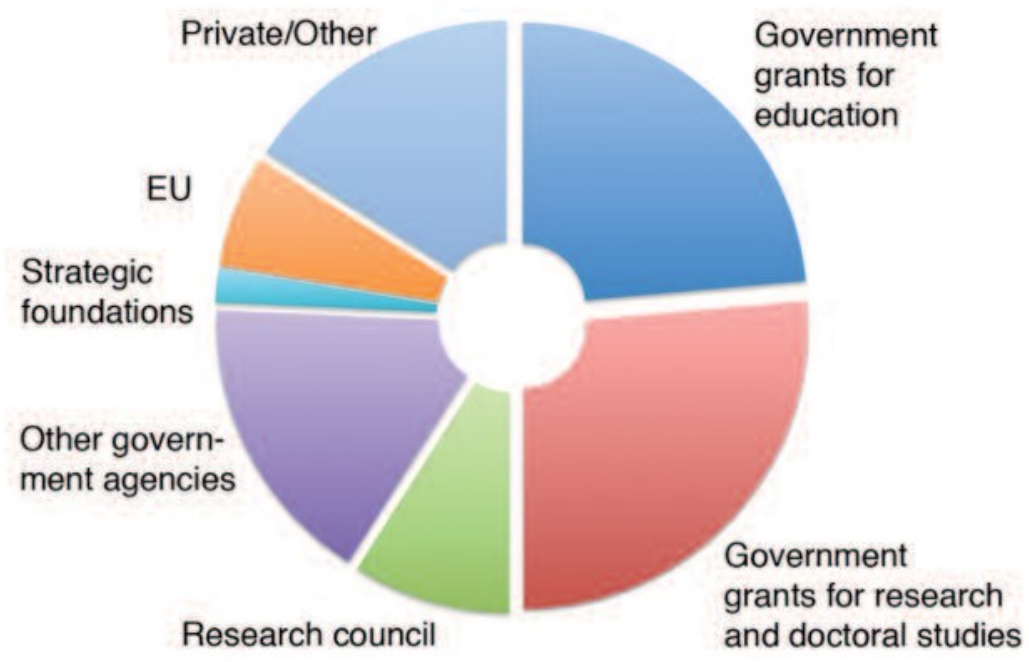

Figure 2: Income sources for KTH Royal Institute of Technology, Sweden 2016. Source: KTH 2016. 


\section{Case Study B}

Nanyang Technological University, Singapore

Nanyang Technological University is a research-intensive university with more than 30,000 students at various levels ranging from undergraduate to postgraduate levels. Considerable institutional support and funding have been devoted to building capabilities in educational technology and course design. Several schools, such as the Nanyang Business School (College of Business), attempt to achieve high quality in both teaching and research by offering two professional tracks for practice (teaching) and research (tenure) faculty. Performance evaluations can be used to indicate the difference in the proportion of time that is devoted to these two endeavours, which typically manifests in practice faculty members spending up to twice the amount of time teaching compared to their research counterparts. This imbalance may impact the ability of schools operating under such a system to deliver an educational experience that integrates research in the teaching curriculum, because practice faculty staff typically do not have significant research experience and/or backgrounds.

Traditionally, funding has been geared towards research rather than teaching activities. However, steps have been taken recently to address this disparity with more funds available at the university level for teaching and pedagogical innovation. The challenge is now to increase awareness for such funding among faculty members, as well as to encourage career researchers to engage more in curriculum and pedagogical innovation.
Recent steps taken to increase funding for teaching and pedagogical development and innovation at the university level in Singapore (Case study B) are encouraging. However, the effectiveness of such developments in addressing the gap between educational content and research is uncertain. Without specific guidance, support and incentives to incorporate research process and insights into the curriculum, there is arisk that these incentives will simply be focused on improving the learning experience and delivery of current, and possibly obsolete, content material. Thus, schools and departments have an important role toplayinadvocatingamoreactiveinclusion of research in student learning experiences. More opportunities should be created for collaborative learning where teaching and research colleagues can interact, learn, and collaborate with each other to design a more research-immersive experience. 


\section{Implementation}

To strengthen the link between education and research, new methods inside and outsidetheclassroomneedtobeintroduced and implemented. However, many teachers and researchers do not have the tools available to create this link, not to mention otherhindrances that render the implementation ofthesemethods difficult. While various programmes have been developed to awaken interest in linking education and research (Bränberg \& Holmgren, 2015), as well as to provide methods, feedback and support, more effort is needed to facilitate the linkage.

The challenges to successfully implementing a strong link between education and research are largely caused by two stumbling blocks faced by course instructors in the development of a bridging program: i) investment of time; and ii) resources needed. To implement research in their conventional courses, instructors need to revamp their curricula and possibly produce new materials.

In addition, linking research to teaching may entail expenditure for consumables, software, equipment, and staff.

The typical research process consists of several steps: development of a research question; selection of methodology; and execution, analysis, evaluation, and finally conclusions. Studentsperformresearchactivities during the learning process within traditional university courses via several modes: academic content; research methods; and practices, as well as the scholarly expertise of the teacher. The teaching can range from a focus on disciplinary content, such as academic writing, literature review, and seminars, to research-process oriented models with educational forms taking problem-based learning (PBL) approaches. The degree of student activity, and research content, in the teaching situation can be described by the Healey model (Healey, 2005), as illustrated in Figure 3.

\section{Students are participants}

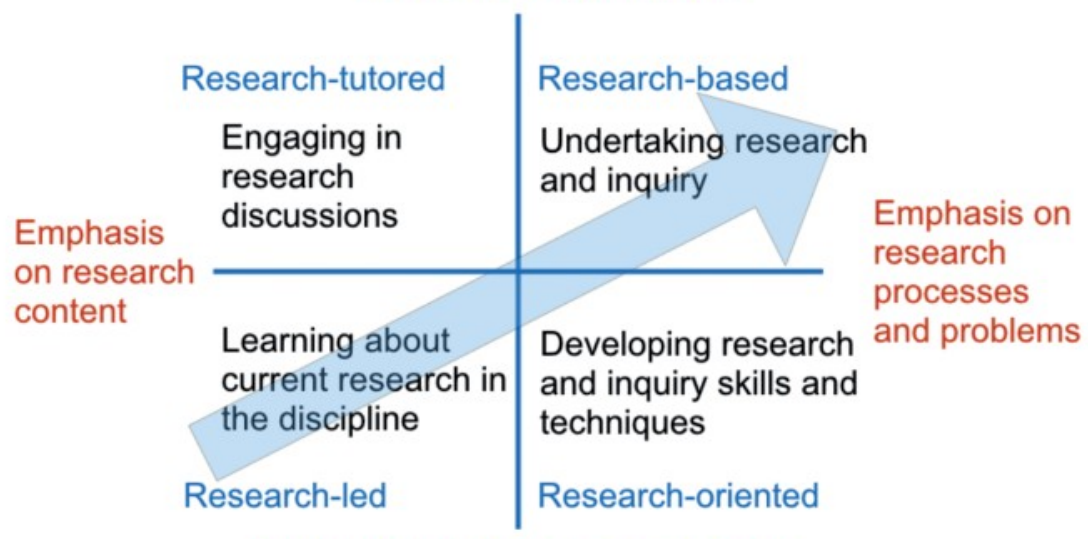

Students frequently are an audience

Figure 3: The Healey model for linking education and research. 
Thus, ifa course chieflyconcerns thetransmission ofresearch content, itcan becategorized as a "research-led" course. In such courses, teachers can inspire students to focusonfundamental problems withafundamental understanding of research, leading to a better understanding of scientific theories. In "research-oriented" courses, methods, such as specific equipment skills and interview skills, are trained. "Research-tutored" learning activities are conducted through research discussions in order to augment tacit interactions amongst students and tutors. Finally, "research-based" teaching involves completing the entire research process cycle, and important steps include framing research questions and evaluating research data along with formulating conclusions. Again, process communications and interactive deliberations are important steps. Amovefrom thelowerleftcornertowards the upper right corner (indicated by the arrow in Figure 3) indicates a stronger focus on knowledgeability.

However, the process of linking education and research is not instantly implemented, but through a series of stages. In the most general sense, we identify three phases to ensure successful implementation:

1. Assess the degree of linkage between education and research in a course or course chain.
2. Analyse and identify good ways of linking education and research.

3. Act on the implementation to link educationandresearch in courses/disciplines wherever applicable.

Herewe focus on the first and second stage of implementation: assessment and analysis. Essentially, these phases require a derivation of a metric that will allow for the systematic measurementof the education and research linkage and identification of methods that will strengthen the link.

Recently, a study(Bränberg \& Holmgren, 2015) was conducted at the Faculty of Science and Technology at Umeå University,Sweden, demonstrating an analysis model in the form of a four-field diagram, similar to the Healey model, but expanded with a progressionscale. The model is a tool thatcan work both for analysis of and as a starting point for discussions about the research content within courses and study programmes. This study shows that such an analysis is feasible and that the results can be both interpreted qualitatively and quantitatively, thus facilitating growth of research attachmentwithin teaching programs. In the following, we use a similar method to analyse the progress of the bioengineering program at Nanyang Technological University (cf. Case Study C). 


\section{Case Study C}

The Bioengineering programme at Nanyang Technological University, Singapore.

One of the most recently designed engineering programmes is the bioengineering program run by the School of Chemical and Biomedical Engineering. To meet the needs of the biomedical and clinical industry, this programmehas been revisited and reformulated, benchmarking other bioengineering/biological-engineering programmes of the top five American Universities, including Massachusetts Institute of Technology and Johns Hopkins University. Basedon bestpractices, the programmeis designed to have a unique three-stage course structure, as shown in Figure 4. The bioengineering programme consists of foundation courses (Year 1), principles courses (Year 2-3) and project courses (Year 4). The foundation courses, including mathematics, chemistry, biology and several introductory courses, provide fundamental knowledge for first-year undergraduate students, training them in basic engineering skills needed for the advanced engineering courses. More biomedical and bioengineering topics are incorporated into the principle courses, guiding sophomoreandjuniorundergraduates to explore bioengineering with sufficient depth. From the second semester of Year 3 , students are gradually exposed to the whole research process, where they set up their own research under the guidance of industry mentors or instructors, propose an approach and conduct experiments, ending up with final projectreports/presentations.

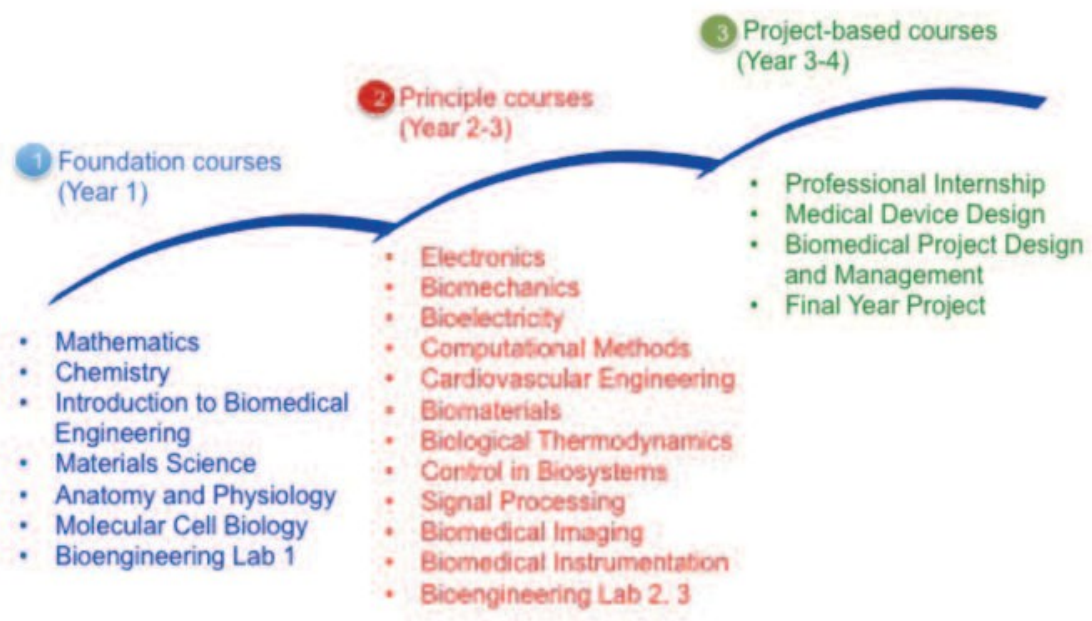

Figure 4: Core courses of the four-year bioengineering programme at the Nanyang Technological University. Source: Nanyang Technological University (2017). 
24 differentcourses in the bioengineering program were analysed and characterized in terms of four categories: whether the course had strong elements of being i) researchled, ii) research-tutored, iii) research-oriented or iv) research-based (See Figure 3). Scores of 0 to 2 were awarded, depending on the level of student participation and the level of research implementation.
Documented course descriptions and faculty interviews were used as raw materials for scoring.

As can be seen from Figure 5, the curriculum of the bioengineering programme progresses from research-led courses to research-based courses over the four-year period, with the aim of moving toward a larger degree of knowledgeability.

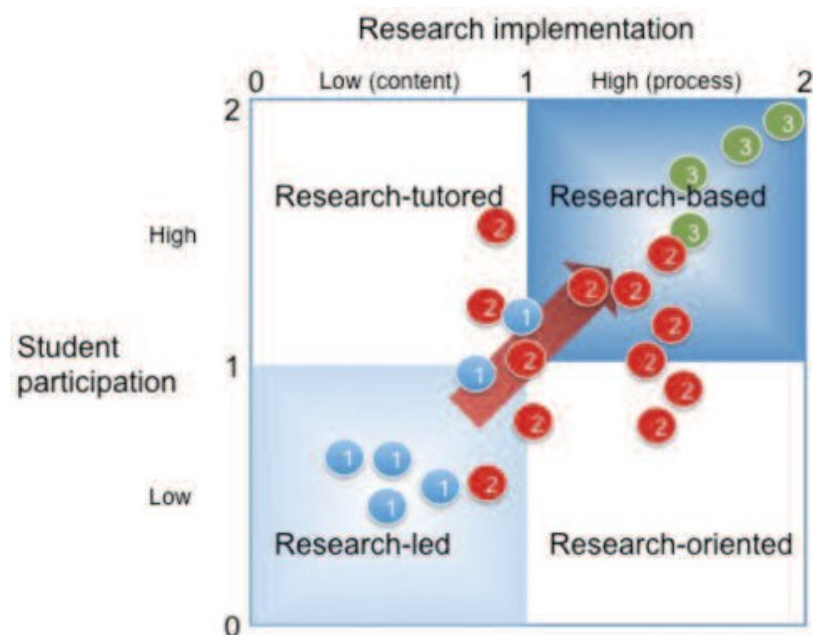

Figure 5: Distribution of selected bioengineering courses on the Healey framework according to the assessment criteria. Number 1 (blue), 2 (red), or 3 (green) each refers to one of the three course stages presented in Figure 5. 
While useful for categorizing a course in terms of its linkage between education and research, the Healey diagram (cf. Figure 3) is ambiguous when the exact placement of a courseon the diagramis to be considered. Often, the user may attempt to classify a coursein onequadrant of the Healey diagram, only to find that an adjacent quadrant may be applicable to the course as well. The solution to this ambiguity is to address the binary mind-seton theHealey diagram, recognizing instead that the linkage between education and research resides on a continuous spectrum within the area enclosed by the four vertices.
The next step is to derive quantifiable measures for the abscissa and ordinate of the Healey diagram, which relate to the type of emphasis on research (content versus processes) and the amount of student participation in the course, respectively.

Up to this point, however, we stilldo not have the capability to identify the methods that promote the linkbetween education and research. To do so, we need to furtherrecognize that the analysis cannot justbe planarbut should be three-dimensional with an additional independent axis to quantifygoodmethods, as shown in Figure 6.

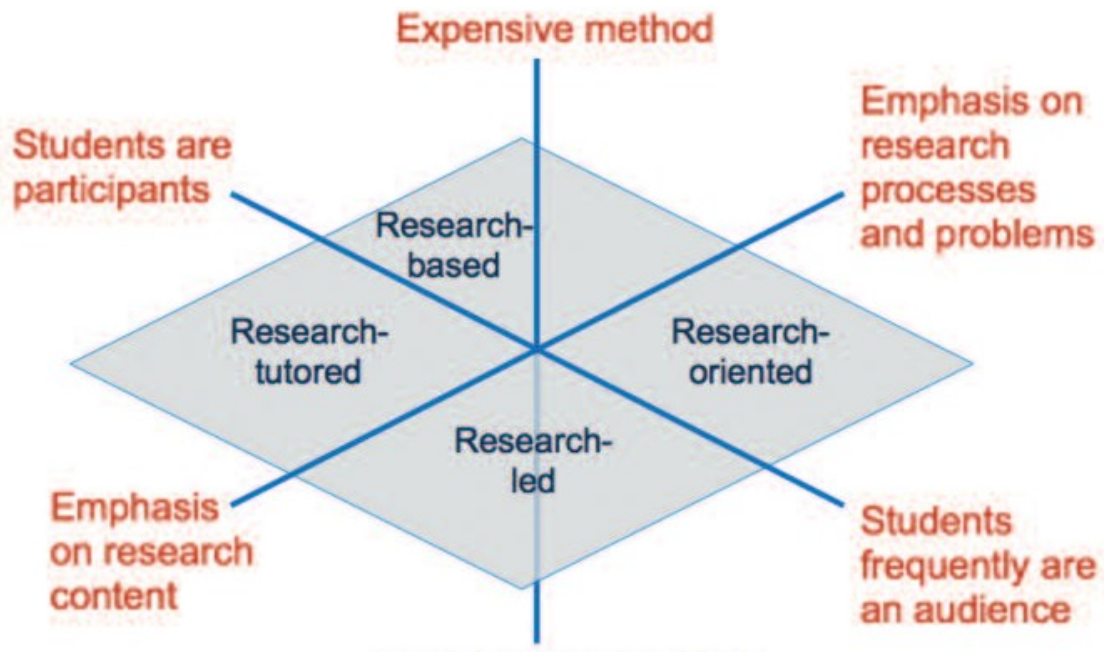

Cost-effective method

Figure 6: An extended Healey model for implementation of the research-education nexus. The shaded plane indicates the original Healey model. 
Like the abscissa of the Healey diagram, the third and so-called "good methods" axisis notrigid, and certainlyopen fordifferent definitions. Forinstance, wecandefinethis axis as the amount of resources required to implementa method, for example the sum of theamountofteachertrainingand financial investment.

Referring to the Healey framework, all four quadrants ofthe research-teaching nexuscan potentiallybeenhancedorenabled by technology. This possibility also means that different disciplines, programme stages and curricula, and even different sections within separate courses, will have different technology needs and consequently resources. Different parameters can serve as determinants to facilitate faster technology incorporation. For instance, large class size is one such parameter that can strain demands on effective communication and interaction in teaching research methods and practices. Another parameteris the curriculacontent.Existing facilitiesandinfrastructurecanalsobeimpact- ful, where a shortage of lecture hallswould mean more interaction beyond classroom spaces that should be resolved by communication technologies. Some examples of applied technologies that enable better integration of teaching and research are: i) infrastructure that could facilitate and augment team-based learning and communication; ii) virtual reality and simulators that could enhance communication of visualizations, execution, and analysis of experiments/cases; iii) different types of sensors to collect data; iv) information technology to enhance social media interface and video calls to increase communications; v) new connective learning platforms to increase pedagogic communication and interaction; and vi) various supporting equipment and tools needed to perform inquiry-based learning in authentic research environments. Below, we discuss threecasestudies with differentdegrees of technology promoting good teaching. The three cases will then be analysed using the extended Healey model.

\section{Case Study D}

Student scholarly project

Medical students of the Lee Kong Chian School of Medicine at the Nanyang Technological University are required to undertake an individual scholarly project at the start of their fourth year. With a total duration of six consecutive weeks, this individual scholarly project aims to enhance students' understanding in a focused area of a medical scholarship and promote scientific inquiries. As a result, the students may be inspired to pursue an academic career inmedicine, forexampleas a clinical scientist or medical educator. In this course, the students are involved participants, personally performing most of the research-related tasks fora sizableamount of time to complete their scholarly project. However, the spread between "research-tutored" and "researchbased" of this method is likely wide because of its open-endedness that gives the students liberty to choose a research-content heavy project over a research-purposes focus one, or vice versa. Therefore, this case is on average more central on the upper-half of the Healey diagram. 


\section{Case Study E}

Student-led conference

At Örebro University, a teaching-focused Swedish university with approximately 15,000 students, about 30 students in the clinical psychology program are required to organize a full-day, professional research conferenceas part of theirterm course on health psychology. To meet the course requirements, the students write a paper on a relevant topic based on a review of the scientific literatureand current practice. The objectives of this conference are to: i) help the students obtain in-depth knowledge in a particular area; and ii) challenge the students to learn to convey their knowledge effectively.

A distinctive feature of this student-led conference is the high level of student participation. The students are involved inallaspectsoforganizing and conducting the conference, thus taking the load off the course instructor. Although we are not moving into the second implementation stage, this time efficiency from a teacher's perspective can be used to gauge the placement along the third axis of the extended Healey diagram in Figure 6.

On the other hand, since this student-led conference focuses more on the development of "soft" research skills, for instance the ability to communicate ideas, disseminate information, foster professional relationships, and stimulate critical analysis, and the

students are collecting data mainly throughliteraturereviewratherthanresearching actively, this case is lower on the scale on the research processes relative to research content.

Collectively, this case then indicates a method that is "research-tutored" on the Healey model, apparently very deep into this quadrant given the conference's aims and scope.

\section{Case Study F}

\section{Discovery-based laboratory practical}

As a part of a virology practical class in the Infection and Immunity course at Karolinska Institutet, a research-intensive medical university in Sweden, the students on the Biomedicine programme are exposed to a three-day discovery-based laboratory practical. In small groups, the students are given four samples of different viruses inunlabelledtubesandareasked toperform experiments to identify the viruses based on informationgiven in theircompendium. The students can design and carry out their own experiments, employing a list of virus laboratory protocols. Through this practical, the students will learn to take on the role of a discoverer, thereby stimulated to adopt a research-based approach in their learnings.

Given the autonomy to design their own experiments, the students are in fact being trained with a research-process heavy approach, even though the virus identification protocols are standard content in the students' compendium. For the same reason, the students are clearly very involved in the practical, actively participating tomeet the courserequirements. Asa result, this case suggests that the discoverybased laboratory practical lies within the "research-based" quadrant of the Healey model, and is a mirroring point to that of Case E. 
Figure 7 shows the placement of the courses, described in case studies D-F, in the Healey diagram, along with their likely spread in the amount of student participation and type of emphasis on research. These cases are clearly successful in shifting towards toan active-learning paradigm, involving students in class participation. In contrast, the cases are more diverse in terms of emphasis on research content or on research processes, highlighting the fact that the Healey classification should not be interpreted as an either/or model.

\section{Emphasis on research content}

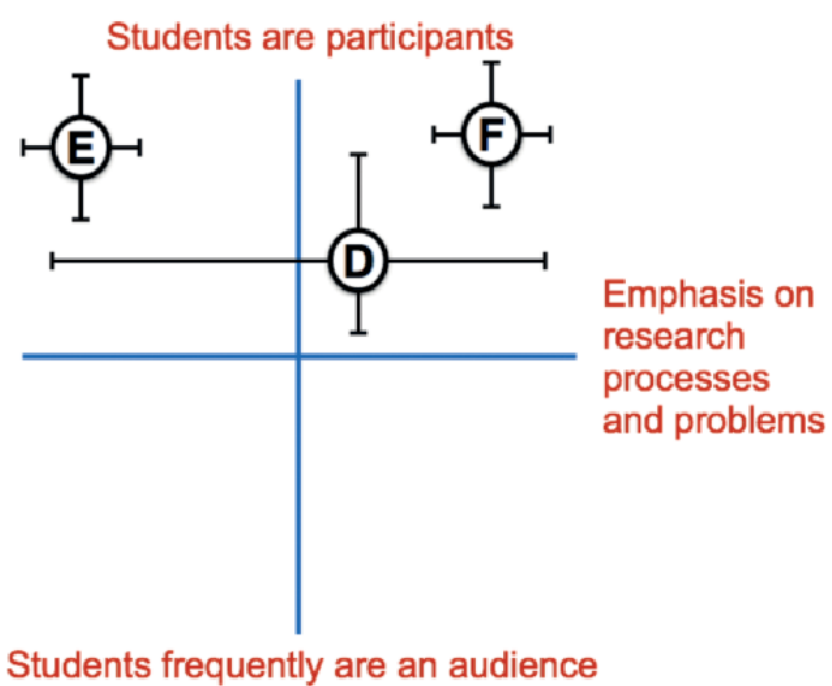

Figure 7: Classification of case studies D-F on the Healey diagram. The potential spread on the diagram is shown to indicate the variance between regimes of each method. 
From Figure 7, there are several analyses in which the second implementation stage can proceed to extract the commendable methods for linking education and research. Following the concept of a third independent axis introduced earlier (See Figure 6), we can rank the three cases based on the amount of resources they require relative to what their corresponding institutes can supply. For example, an institution that has inadequate funding or manpower may value the student-led conference (Case E) over the individual scholarly project (Case D), which can be overwhelming to the instructor in terms of guiding and grading the project deliverables, or the laboratory practical (Case F) which may be costly due to consumable reagents and equipment that need to be maintained. Generally, the cost involved in running inquiry-based research projects within the confines of a traditional laboratory course far exceeds the typical laboratory course budget. Besides the instructor needing to have an active research environment with sufficient equipment and infrastructure, graduate students and teaching assistants to tutor the student groups, and space to host the student groups in the research laboratories, one must also have suitable research funding with grants that allow the incorporation of the research questions posed by the student groups and the results they obtain.
With a systematic determination of the placement of courses in the Healey diagram, the Healey model can also be used for monitoring courses in a discipline and tracking progression of a course/method in linking education and research. In addition to a strong research connection within a course chain, a shift is increasingly seen in the role of students from passive information recipients to active knowledge producers. This evolution can be categorized by Domin's definitions of laboratory-based instruction style in accordance with the degree of high-order thinking that is being promoted (Domin, 1999). Specifically, the various styles, namely "Expository", "Inquiry", "Discovery", and "Problem-based learning", involve different levels of student participation and hence transfer different degrees of "ownership" of an activity to the students. Berg et al. (2003) investigated the effects on the student learning outcomes by the degree of openness of course instructions to the samelaboratory activity. In general, open inquiry-driven laboratory activities result in the most positive learning outcomes and engagement among students. Thus, the implementation of the research process into a teaching course will be further supported by a more active-learning mind-set. 


\section{Quality assessment}

In Sweden, the Higher Education Ordinance comprises national qualitative targets for all degrees that higher education institutions mayaward. Thequalitativetargetsare divided intothreecategories:knowledgeandunderstanding, competence and skills, and judgement and approach. For professional programmes, there are specific qualitative targets related to the students' future professional careers.

On a national level, the quality of highereducationandresearchismonitored and assessed by the independent Swedish HigherEducation Authority, which operates directly under the Ministry of Education and Research. As mentioned above, all higher education shall be based on an academic or artistic foundation and proven experience, meaning that there should be a link between education and research. The Swedish HigherEducation Authority and universities have a shared responsibility for monitoring thequality ofboth teaching/learning activities and research.

During the period of 2011 to 2014, the Swedish Higher Education Authority evaluated 2,200 bachelor and master programmes (UKÄ, 2015). The evaluation hada strong focus on the learning outcomes achieved and relied heavily on student theses.

A large portion of the programmes assessedas being ofinadequatequalityin this national evaluation were censured primarily because of their weak link to research.
Reviewers commented, for example, on how students' thesis projects demonstrated insufficient familiarity with the relevant methodology and formal requirements. Other comments expressed concern about the students' analytical skills, their capacity to identify problems and define research questions and their ability to reach wellgrounded conclusions (UKÄ, 2017). Several programmes assessed as having very high quality, on theotherhand, werecharacterized by a strong research environment where the students carried out their thesis projects under the strict guidance of senior researchers.

While this evaluation model is limited due to its heavy reliance on thesis projects,

it nonetheless had some effects on strengthening the links between education and research. Methodology courses were developed, theoretical and scholarly discussions were introduced, greater attention was paid to research skills and higher qualifications were required of supervisors and examiners.

Upon the completion of this cycle of programme evaluations, the Swedish Higher Education Authority developed a new national system for quality assurance in higher education. Within a six-year period, a third of the doctoral programmes and all Swedish highereducation institutions will be reviewed. 


\section{Case Study G}

Assessing links between education and research on a national level in Sweden

Some assessment criteria in the new Swedish system for quality assurance aim at evaluating the link between education and research. For example, for third-cycle (doctoral) programmes to meet the assessment criteria for the aspect "Achievementof qualitative targets for competence and skills", the higher education institutions have to show that the programme, "Through its design, teaching/learning activities and examination [...] ensures that doctoral students whose degrees have been awarded can plananduseappropriate methods to conduct research and other qualified(artistic)taskswithinpredetermined time frames, and in both the national and the international context, in speech and in writing authoritatively, can present and discuss research and research findings in dialogue with the academic community and society in general". Hence, within the third-cycle programme evaluations, the links between education and research can be highlighted through the doctoral students' achievement of the qualitative targets for transversal skills used as criteria for assessing quality. Educational quality is in this way associated with the links between education and research.

In addition to programme evaluations, thenew national system for quality assurance includes institutional reviews, which are still being piloted. Attempts have also been made to capture the link between education and research in the institutional reviews. The clearest example of this can be found within the quality aspect "education and research". This assessment criterion states that the higher education institution must show that it "ensures that there is a clear link between education and research in the learning environment". Furthermore, the institution under review must show that it "has transparentand legally secure processes for recruiting faculty, and that scientific or artistic competence and pedagogic or other competence are treated with equal care". To meet the assessmentcriterion, the institution must show that it "works systematically to follow up, assess and enhance the link between education and research in the learning environment".
The effects of the new Swedish system for quality assurance (Case Study G) remain to be seen, sinceinstitutional reviews are still in the pilot phase and outcomes of the evaluation of doctoral programmes are not yet known. As a result, the expectation that the assessment criteria linking education and research will strengthen the connection between the two processes is unverified. However, based on experience from the lastround of programmeevaluations, which put the qualitative targets on thenationalagenda, a tentativehypothesis can be made: by highlighting the education/research nexus through the assessment criteria discussed above, the national evaluations can contribute to strengthening links between education and research.

In 2006, Singapore's public universities, such as the National University of Singapore and Nanyang Technological University, were given greater flexibility in deciding on matters such as internal governance, budgetutilization, tuitionfees, and admission requirements $(\mathrm{Lo}, 2010)$. 
However, these autonomous universities need to maintain alignment of their strategic directions with the national strategic objectives (Ng\&Tan,2010).Regulationoftheoverall management of autonomous universities is exercised through various quality assurance and performance evaluation measures $(\mathrm{Li}$, Huang \& Widiastuti, 2012). In summary, thePolicy Agreementensuresthat theuniversities are aligned with the national development needs, the Performance Agreements leads to the continual improvement, and the Quality Assurance Framework instills accountability. The autonomous universities are monitored for their quality of teaching as well as research through this national framework. Strengthening the research-education links is often one of the strategies adopted by the universities to achieve exellence in both teaching and research. See Case Study $\mathrm{H}$ for an example of how the Quality Assurance Framework can beimplemented.

\section{Case Study $\mathrm{H}$}

Quality assurance at the National Institute of Education, Singapore.

The National Institute of Education (NIE) in Singapore has a strong tripartite relationshipwith the Ministry of Education and its primary and secondary schools. In just over a decade, NIE transformed from a teacher training institute focusing primarily on teaching to a research-intensiveinstitute with balanced teaching and research activities. Given the NIE's research focus on pedagogy anditsnationalagendainteachereducation, the education-research links involve two aspects. The first is the link between teacher and research education within the NIE, which is similar to the educationresearch link in most universities. This link is manifested both in terms of content (e.g. what new pedagogies student teachers need to learn) and the teaching methodology and pedagogy (e.g.how student teachers are taught this content). Second, the educationresearch link also dictates the link between Singapore's general education and research. This link is often regarded as research impact (or a research-practice link) in most universities.
One way of monitoring the educationresearch links is to observe student outcomes as a result of the strengthened links. A complementary approach is to monitor the extent to which the links are consistently manifested in the institution's strategy, quality assurance framework, and enhancement activities

In the NIE research framework, the education context and priorities in Singapore shape research questions and priorities (i.e. the link from education to research), and research findings inform the enhancement of student performanceand organizational outcome in Singapore schools (i.e. the link from research to education).

The TeacherEducation Model for the $21^{\text {st }}$ Century $\left(\mathrm{TE}^{21}\right)$ is another manifestation of how teaching and research are linked. This model focuses on three value paradigms:(i) learner-centred;(ii) teacher identity; and (iii) service to the profession and community. Under the $\mathrm{TE}^{21}$ model, the National Institute of Education also developed an extended pedagogical repertoire to address the theory-practice gap and strengthen the link between teacher education and research. 


\section{Case Study H (continuation)}

With the improvement of content (e.g. the specific professional standards, benchmarks, and goals for the NIE graduates) and pedagogy (e.g. the extended pedagogical repertoire), the assessment of student outcomes is enhanced under $\mathrm{TE}^{21}$. The explicit articulation of $\mathrm{TE}^{21}$, in terms of the programme goal, curriculum, pedagogy, assessment, transformation of learning infrastructure and faculty peer-evaluation, guides its implementation. In turn, these factors can be used to monitor the quality of education-research links at multiple levels.

Channels for communicating research findings to policy makers, teachers, and academic staff within the National Institute of Education are also being improved. For example, SingTeach is an e-magazine published by the Institute for teachers in Singapore that brings together current research in education and the best classroom practices, thus putting research within the reach of Singapore's teachers so as to inform practice. The NIEResearchBrief Series is aimed at research-to-practice translation, that is, the dissemination, implementation, and diffusion of research findings that impact policy and practice. The more recent publication, Knowledge Bites, aims to share education research discussions and issues as seen in the Singapore context. These publications serve as a platform for sharing thoughts and concepts of education research with policymakers, educators, and the public.

\section{Summary and conclusions}

Overall student performance, for example in critical thinking and problem solving, can be improved if research-related activities are incorporated into the curriculum and used in everyday teaching. However, although there are many examples of methods for quality assurance of teaching and measures of the quality of research, there are few instances of where the linkage between the two is assessed. Different versions of the Healey model are useful for characterizing courses, but it is less advantageous to use the model for ranking purposes since all four types of research-education links are necessary and useful to providean enriched learning experience. Furthermore, there is no simpleway of formulating metrics for measuring the quality of the education/research nexus, and it is thus difficult to define one specific way for quality assurance. Instead, measures forimprovingthequality of thelinks between education and research must be adapted to the specific context, both politically and in terms ofdisciplineas wellashighereducation institutions. Importantly, the act of evaluating the link between education and research can increase awareness of this linkage for both teachers and researchers. In turn, this awareness may strengthen the link and contribute to even higher quality education and research. One effective way of strengthening the link between education and research is hence to formulate specific criteria for assessing the quality of both educational programmes and research. 
This article introduces a three-stage procedure to systematically implement the linkage between education and research, consisting of: i) assessment of the extent of linkage; ii) analysis and identification of methods promoting linkage; and iii) acting on the implementation of the linkage. Focusing specifically on the first stage, an extended Healey model is derived to facilitate implementation of a strong linkage between education and research in a course or study programme. Therelevance of themetric is further demonstrated using case studies, along with the various ways that the extended Healey model can be employed to proceed into the remaining two stages of implementation.

Different integrative technologies can be used to enhance the links between teaching and research. Several of these technologies already exist and are used conventionally, often forimproving teaching and learning in general. Most common are technologies that improve pedagogic communication exchanges, such as learning platforms, immediate interaction equipment and performance software. More advanced technologies, such as virtual reality simulators, need to be further developed, which can be useful for larger student classes that may assert limitations on infrastructure conditions. Furthermore, it will be critical to consider the inputs of training, service, and support with new technology to overcome the overall the reluctance of students, teaching staff, and faculty members, thus ensuring fast and sustainabletransitions.

At the national level, there is aclear issue of funding for programmes to integrate teaching andresearchintertiary education. Sweden, for example, has separate budgets for education and research. The balance between the two areas varies across universities, in accordance with the size and focus of the higher education institutions. In addition, many research-intensive universities are strongly dependent on external funding.
Whenfacultymembersdependonexternal funding for theirbasicsalaries, theincentive to engage in anything other than research is naturally low. The funding structure should therefore be geared towards incentivizing teaching effectiveness. Promotion and tenurerequirements can also be aligned to better reflect the importance of both teaching and research across different schools. The financial reasons for the low priority of education seen at some universities need to be targeted at all levels. Combining the direct funding of education and research allocated to Swedish higher education institutions would give each university a better possibility to prioritise. Another plausible strategy will be to assign a targetnumber of graduates that must be produced each year.

Beyond funding, there is a clear need for institutional reorganization to redress the balance regarding teaching and research in the academic sector. Support in the form of educational technicians and instructors is essential to improve student engagement in learning research content and processes, which may be perceived as inaccessible. Open seminars and a more accessible environment where researchers and students from different areas and levels can meet and interact will be beneficial for integration.

In conclusion, the successful implementation of the linkagebetweeneducationand research will not be straightforward, but certainly rewarding. Most cases show that a strengthened link between education and research enhances the concept of "knowledgeability". However, patiencewillbecrucialifsuchanundertaking is to succeed, because the process will inevitably be iterative, requiring the integration of all parties in a cyclical manner and through constant revisions. This work is still far from complete, and instead this is only the beginning of a much longer-term effort required sothatthelinkbetweeneducationandresearch finally can materialize. 


\section{References}

Bell, D. (1973). The Coming of Post-Industrial Society. New York, NY: Basic Books.

Berg, C.A., Bergendahl, V.C., \& Lundberg, B.K. (2003). Benefiting from an open-ended experiment? A comparisonofattitudesto, and outcomes of, an expository versus an open-inquiry version of the same experiment. International Journal of Science Education 25(3), 351-372.

Bränberg, A., Holmgren, U. (2015). Forskningsanknytning av grundutbildning: En praktisk analysmetod. 5:e Utvecklingskonferensen för ingenjörsutbildningar: Proceedings (pp. 51-55). Uppsala: UppsalaUniversitet.

Böhme, G. and Nico Stehr, eds. (1986). The Knowledge Society: The Growing Impact of Scientific Knowledge on Social Relations. Norwell, MA: D. Reidel Pub. Co.

Committee on University Education Pathways Beyond 2015. Report. Available at: https://www.moe.gov.sg/news/committee-onuniversity-education-pathways-beyond-2015

Domin, D. S. (1999). A review of laboratory instruction styles. Journal of Chemical Education 76, 543-547.

Etzkowitz, H., Leydesdorff, L. (1995). The Triple Helix:University- Industry- Government Relations: A Laboratory for KnowledgeBasedEconomic Development. EASSTReview 14, 14-19.

Geschwind, L., Magnell, M., Söderlind,J. (2016). Kopplingenmellan forskning ochutbildning på KTH. Report. Available at: http://www.diva-portal.org
Healey, M. (2005). Linking research and teaching: Exploring disciplinary spaces and the role of inquiry-based learning. In R. Barnett, Reshaping the University: New Relationships between Research, Scholarship and Teaching (pp. 67-78). Maidenhead, UK: Open University Press.

KK-stiftelsen (2016). Forskningsperformance vid Sveriges universitet och högskolor. Report. Available at: http://www.kks.se/om-oss/pressoch-publikationer/publikationer/

KTH Annual report (2016). Available at: https://www.kth.se/polopoly fs/1.717560!/S KC_Annual_report_2016.pdf

Lee, W. O., Huang, J. S., Widiastuti, A. (2012). The parallel of institutional autonomy and state governance in higher education in Singapore. In A. Xie \& N. L. Lei (Eds.), The construction of a modern university system: University governancein theoryandpractice (pp.40-54). Macao: Macao Polytechnic Institute.

Lo, Y. W. W. (2010). Entrepreneurialism in Higher Education: A Comparison of University Governance Changes in Hong Kong and Singapore. In The Search for New Governance of Higher Education in Asia (pp. 103-123). New York, NY. Palgrave Macmillan.

Nanyang Technological University (NTU), School of Chemical and Biomedical Engineering (SCBE) program requirement Bioengineering (BIE) course description. Available at: http://www.scbe.ntu.edu.sg/Programmes/Cur rentStudents/undergraduate/Programme $\% 20$ Requirements/Pages/AY2016-2017\%20Intake.aspx 
Ng, P. T., Tan, C. (2010). The Singapore global schoolhouse: An analysis of the development of the tertiary education landscape in Singapore. International Journal of Educational Management, 24(3), 178-188.

Ranga, M., Etzkowitz, H. (2013). Triple Helix Systems: An Analytical Framework for Innovation Policy and Practice in the Knowledge Society. Industry and Higher Education 27(4), 237-262.

Stehr, N. (1994). Knowledge Societies. London, UK: Sage Publications.

Stehr, N. (2008). Knowledge and Democracy: A 21st Century Perspective. New Brunswick, N.J: Transaction Publishers.

UKÄ (2015). The effects of programme evaluations. Report. Available at:

http://english.uka.se/download/18.6b3261a3 15a296ca0f3dc4cb/1487932593265/Effectsof-programme-evaluations.pdf

UKÄ (2017). Erfarenheter och lärdomar av kvalitetsutvärderingar 2011-2014. Report. Available at: http://www.uka.se/om-oss/publikationer--beslut/rapporter/rapporter/201706-28-erfarenheter-och-lardomar-av-ukas-kva litetsutvarderingar-2011-2014.html

Välimaa,J.,Hoffman,D.(2008).Knowledge Society Discourse and Higher Education. Higher Education 56(3), 265-285.

Winka, K. (2017). Kartläggning av pedagogiska meriteringsmodeller vid Sveriges högskolor och universitet. PIL-rapport 2017:02 Göteborgs universitet. Report. Availableat:http:/hdl.handle.net/2077/53276 